УДК 65.011

\title{
ОРГАНИЗАЦИОННО-ЭКОНОМИЧЕСКИЙ МЕХАНИЗМ СТРАТЕГИЧЕСКОГО УПРАВЛЕНИЯ ИННОВАЦИОННО-ОРИЕНТИРОВАННЫМ РАЗВИТИЕМ ПРОМЫШЛЕННЫХ ПРЕДПРИЯТИЙ
}

\author{
(ㄷ) 2012 г. К. П. Москвитин
}

\section{Московский государственный технологический университет «СТАНКИН»}

В статье рассматриваются основные компоненты организачионно-экономического механизма и задачи стратегического управления инновачионно-ориентированным развитием промышленных предприятий, представлены инструменты решения указанных задач.

Ключевые слова: инновационно-ориентированное развитие; стратегическое управление; организационно-экономический механизм; промышленные предприятия.

In the article author discusses the main components of the organizational and economic mechanism and tasks for the strategic managing of the industrial enterprises' innovation development, and also presents some tools, which can be useful for solving the aforesaid tasks.

Key words: innovation development; strategic management; organizational and economic mechanism; industrial enterprise.

Признание стратегии инновационного развития Российской Федерации объективно необходимой и приоритетной, принятие данной стратегии в качестве стратегии развития России на двадцатилетний период, и выбор варианта достижения лидерства в ведущих научно-технических секторах и фундаментальных исследованиях предопределяет необходимость конкурентного стратегического управления инновационным развитием предприятий, осуществляющих выпуск авиакосмической техники. В свою очередь, конкурентное стратегическое управление инновационным развитием невозможно без разработки и реализации соответствующего организационно-экономического механизма, требующее его структуризации.

Под организационно-экономическим механизмом будем понимать систему стратегического управления инновационным развитием промышленного предприятия, учитывающую особенности организационной модели промышленного предприятия, экономику бизнес-процессов и финансовые результаты инновационного развития предприятия.
Важными аспектами конкретизации и структуризации организационно-экономического механизма стратегического управления инновационно-ориентированным развитием (ОЭМСУИР) является определение:

- целей стратегического инновационного развития предприятия;

- условий функционирования механизма, к которым следует отнести условия запуска, приостановки и остановки механизма.

В качестве интегральной цели стратегического инновационного развития предприятия выступает максимально возможный рост фундаментальной стоимости предприятия. Локальными целями инновационного развития предприятия является максимально возможный прирост стоимости технического капитала предприятия, и обеспечение финансовой устойчивости предприятия при реализации стратегии инновационного развития $[1 ; 2]$.

К условиям запуска механизма отнесем: выбор и/или начало реализации стратегии инновационного развития; разработки/реализации инновационного портфеля или ин- 
новационного проекта; начало функционирования инновационного/инновационно-ориентированного предприятия.

Условия приостановки ОЭМСУИР: приостановка реализации стратегии инновационного развития предприятия, приостановка реализации инновационного портфеля; приостановка деятельности инновационного (инновационно-ориентированного предприятия).

Условиями остановки механизма являются: смена стратегии инновационного развития предприятия; ликвидация инновационного (инновационно-ориентированного) предприятия.

Исходя из принятого определения ОЭМСУИР предприятия структурируется в разрезе двух элементов: управляемой и управляющей подсистем; технологии и организации управления.

Структурная особенность предлагаемого ОЭМСУИР заключается в том, что проекции технологии и организации управления на управляемую и управляющую подсистемы определяют базовые компоненты (объект и субъект управления) и организационноуправленческий инструментарий (процедуры, инструменты, структуры) механизма.

Конкретизация объекта управления осуществляется при проекции технологии на управляемую подсистему, а субъекта - при проекции организации управления на управляющую подсистему. Совокупность организационного инструментария определяется при проектировании организации управления на управляемую подсистему, а управленческого инструментария - при проектировании технологии управления на управляющую подсистему.

Элементами управляемой подсистемь ОЭМСУИР, т. е. объектами управления являются: формы, типы и стратегии инновационного развития; риски, связанные с инновационным развитием предприятий; портфель инновационных проектов и инновационный проект. В соответствии с хорошо известными формами, типами и стратегиями развития предприятия целесообразно выделять следующие стратегии инновационного развития предприятия: интенсивная стратегия генератора; интенсивная стратегия инноватора; интенсивная стратегия имитатора; смешанная стратегия инноватора; смешанная стратегия имитатора; экстенсивная стратегия имитатора; интенсивная стратегия консерватора; смешанная стратегия консерватора; экстенсивная стратегия консерватора.

Критерием выбора наиболее адекватной стратегии инновационного развития является максимальное достижение указанных выше целей (интегральной и локальных) инновационного развития предприятия. При этом важной задачей является уточнение предлагаемых стратегий инновационного развития для российских предприятий на отечественном и мировом рынках, т. е. с учетом российской и мировой классификацией инновационных (инновационно-ориентированных) предприятий [2].

Среди частных объектов управления, т. е. частных элементов управляемой подсистемы, требующих специального исследования, являются риски. К рискам, связанным с инновационным развитием предприятия авторы относят группы рисков организационно-технологической и кадровой готовности предприятия, проектные риски (риски проектов по созданию и освоению инноваций), риски действия менеджмента, трансфертные риски, политико-правовые риски и некоторые другие $[3 ; 4 ; 5]$. При этом в качестве основы для осуществления комплексной и системной классификации рисков используется подход, базирующийся на учете:

- трех этапов жизненного цикла создания и освоения инновации (НИОКР, техническая подготовка производства, освоение инноваций);

- характерные признаки готовности технологий (уровень готовности менеджмента, уровень готовности техники, уровень готовности интеграции, уровень готовности программного обеспечения, уровень операционной готовности; уровень готовности персонала, Уровень организационной готовности);

- ресурсов (видов и объемов), требуемых для реализации выбранной стратегии инновационного развития.

Управление рисками каждой из указанных групп помимо традиционных методов оценки предполагает использование специфических методов и инструментов таких, например, как стратегическое хеджирование.

Элементами управляющей подсистемь, 
т. е. субъектами управления являются элементы внутренней и внешней среды предприятия, осуществляющие непосредственно или способствующих реализации бизнеспроцессов управления инновационным развитием и трансферта инноваций. К субъектам ОЭМСУИР следует отнести: службы и подразделения предприятия напрямую или косвенно связанные с осуществлением стратегического и стратегического инновационного развития предприятия; службы и организации федерального, регионального и муниципального уровней, реализующие и/ или поддерживающие программы и проекты инновационного развития промышленных предприятий [6].

Такой элемент ОЭМСУИР как «технология управления» представляет совокупность управленческих инструментов, обоснованный выбор и адекватное применение которых позволит осуществлять процесс стратегического инновационного развития наиболее рационально с достижением максимально возможных финансовых результатов. К наиболее значимому оригинальному инструментарию, предлагаемому авторами, следует отнести:

- разработка структурной и функциональной схем управления стратегическим инновационным развитием предприятия на основе стоимостного подхода к управлению;

- организационно-управленческий инструментарий риск-менеджмента, позволяющий управлять рисками и предотвращать кризисы, связанные с инновационным развитием предприятия;

- управленческий инструментарий поддержания финансовой устойчивости предприятия, реализующего стратегию инновационного развития, который дифференцирован по девяти указанным выше стратегиям инновационного развития.

Декомпозиция элемента «организация управления» позволит определить перечень процессов и задач инновационного развития предприятия по уровням и субъектам управления, как во внутренней, так и во внешней среде предприятия. Среди наиболее значимых задач следует отметить: мотивация персонала предприятия к инновационному развитию, повышению стоимости технического капитала предприятия; выбор и реализация форм и методов трансферта и продвижения инновационных разработок.

Рассмотренные элементы организационно-экономического механизма, а также перечень традиционных основных задач стратегического менеджмента и их интерпретация применительно к стратегическому управлению инновационно-ориентированным развитием промышленных предприятий (ИОР ПП), позволили установить инструменты, применяемые для решения соответствующих задач (табл. 1).

Таким образом, разработка выделенных элементов и компонент структурированного ОЭМСУИР предприятий позволяет сформировать совокупность организационно-управленческого инструментария сбалансированного и конкурентного стратегического управления инновационным развитием промышленных предприятий.

\section{Литература}

1. Бадалова А. Г., Шебаров А. И. Методология организации управления инновационно-ориентированным развитием промышленных предприятий. Монография. - М.: «Янус-К», 2010. - 228 с.

2. Стратегическое управление инновационно-ориентированным развитием промышленных предприятий. Монография. / Под ред. А. Г. Бадаловой и М. Е. Просвириной. - М.: ВПО МГТУ «СТАНКИН», 2012. $-109 \mathrm{c}$.

3. Бадалова А. Г., Москвитин К. П. Управление кадровыми рисками предприятия. // Российское предпринимательство. 2005. - №7. - С. 92-98.

4. Бадалова A. Г. Методологические основы оценки и управления рисками, связанными с инновационным развитием промышленных предприятий. // Управление корпоративной культурой. - 2012. — №4. - 27 c.

5. Бадалова А. Г., Пантелеев П. А. Обоснование выбора предпочтительной стратегии управления риском на основе метода анализа иерархий. // Научное обозрение. Экономика и управление. - 2011. - №5. - С. 657-669. 
Таблица 1

Задачи инструменты стратегического управления ИОР ПП

\begin{tabular}{|c|c|c|c|}
\hline $\begin{array}{l}\text { № } \\
\text { ПП }\end{array}$ & $\begin{array}{c}\text { Основные } \\
\text { задачи }\end{array}$ & $\begin{array}{c}\text { Применяемые } \\
\text { инструменты }\end{array}$ & Цель/результаты решения задачи \\
\hline 1 & 2 & 3 & 4 \\
\hline 1. & $\begin{array}{l}\text { Анализ } \\
\text { факторов } \\
\text { внешней и } \\
\text { внутренней } \\
\text { среды }\end{array}$ & $\begin{array}{l}\text { Расширенная } \\
\text { матраца SWOT- } \\
\text { анализа для } \\
\text { ИОР ПП }\end{array}$ & $\begin{array}{l}\text { Выявление факторов внешней и внутренней сре- } \\
\text { ды ПП, позволяющие определить потенциальные } \\
\text { направления и проблемные поля развития, а так- } \\
\text { же связанные с ними риски }\end{array}$ \\
\hline 2. & $\begin{array}{l}\text { Установле- } \\
\text { ние целей } \\
\text { развития }\end{array}$ & $\begin{array}{l}\text { Метод иерархии } \\
\text { целей (дерево } \\
\text { целей) }\end{array}$ & $\begin{array}{l}\text { Структуризация целей развития ПП по направ- } \\
\text { лениям развития, расчет дерева целей по вы- } \\
\text { бранным параметрам и установление наиболее } \\
\text { приоритетных направлений с учетом состояния } \\
\text { внешней и внутренней среды ПП и возможных } \\
\text { ресурсных ограничений }\end{array}$ \\
\hline 3. & $\begin{array}{l}\text { Выбор } \\
\text { стратегии } \\
\text { ИОР ПП }\end{array}$ & $\begin{array}{l}\text { Экспертно- } \\
\text { аналитический } \\
\text { метод, метод ана- } \\
\text { лиза и синтеза, } \\
\text { матрица вы-бора } \\
\text { стратегии ИОР }\end{array}$ & $\begin{array}{l}\text { 1. Разработка совокупности базовых и частных } \\
\text { стратегий ИОР ПП. } \\
\text { 2. Разработка матрицы выбора стратегии ИОР } \\
\text { ПП. } \\
\text { 3. Анализ альтернативных и выбор приоритетной } \\
\text { стратегии ИОР ПП. }\end{array}$ \\
\hline 4. & $\begin{array}{l}\text { Перевод } \\
\text { стратегии } \\
\text { ИОР ПП в } \\
\text { систему чет- } \\
\text { ко постав- } \\
\text { ленных це- } \\
\text { лей, задач и } \\
\text { показателей } \\
\text { реализации } \\
\text { стратегии }\end{array}$ & $\begin{array}{l}\text { Сбалансирован- } \\
\text { ная карта оценок } \\
\text { состояния } \\
\text { ИОР ПП }\end{array}$ & $\begin{array}{l}\text { 1. Определение и распределение планируемых } \\
\text { параметров / показателей ИОР до подразделений } \\
\text { всех уровней управления ПП. } \\
\text { 2. Определение ключевых показателей /критериев } \\
\text { эффективности ИОР ПП и оценка на их основе } \\
\text { результативности деятельности соответствующих } \\
\text { подразделений ПП. } \\
\text { 3. Выявление, оценка и управление рисками, свя- } \\
\text { занными с ИОР ПП. }\end{array}$ \\
\hline
\end{tabular}

6. Бадалова А. Г., Еленева Ю. Я., Шебаров А. И. Инновационное развитие промышленного производства: методология органи- зации управления. // Вестник МГТУ «Станкин». - 2010. — №4 (12). - С. 158-162.

14 октября 2012 г. 


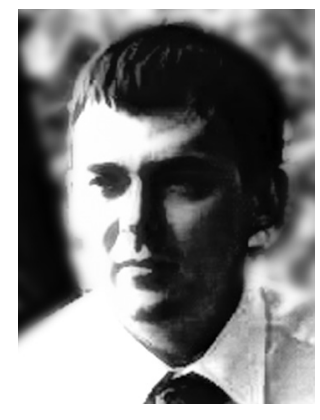

Константин Петрович Москвитин - соискатель Московского государственного технологического университета «СТАНКИН», ведущий экономист ОАО «Корпорация «Комета».

Konstantin Petrovich Moskvitin - competitor for the Candidate's degree at the Moscow State Technical University «STANKIN», the leading economist of the «Kometa» Corporation» public corporation.

123030, г. Москва, ул. Нижняя Масловка, д. 6, кв. 37

6 Nizhnyaya Maslovka st., app.37, 123030, Moscow, Russia

Тел.: +7 (926) 562-85-87; e-mail: moskvitink.82@mail.ru

\section{Уважаемые коллеги! \\ 17-18 октября 2013 г.приглашаем вас принять участие \\ во Всероссийской научно-практической конференции с международным участием «Актуальные проблемы социокультурной практики»}

Прием материалов до 1 сентября 2013 г.

Цель конференции - обсуждение актуальных проблем современной социокультурной практики; публикация результатов исследований ведущих ученых, аспирантов, докторантов и практиков социально-культурной сферы; установление контактов между учеными разных стран, обмен научными результатами и исследовательским опытом.

Рабочие языки конференции - русский и английский.

К участию в конференции приглашаются руководители, специалисты, преподаватели, докторанты, аспиранты образовательных учреждений любой ведомственной принадлежности и организационно-правовой формы, руководители и специалисты предприятий и организаций, а также все лица, проявляющие интерес к рассматриваемым проблемам.

Организатор: Восточно-Сибирская государственная академия культуры и искусств

Контактный телефон: +7 (3012) 23-29-83 